\title{
Rat model of cardiopulmonary bypass for deep hypothermic circulatory arrest
}

\author{
Tom Waterbury, MPS, CCP, LP, Thomas J. Clark, BS, Scott Niles, BS, and Robert Saeid Farivar, MD, PhD, \\ Iowa City, Iowa
}

Large animal cardiopulmonary bypass (CPB) models have disadvantages, such as cost, lack of methods for assessment of neurocognitive function, and difficulties with long-term recovery. As a result, rodent models have been developed. ${ }^{1-4}$ Previous rodent models have certain drawbacks, including irrelevance to human flows used clinically. We established a clinically relevant model of CPB with deep hypothermic circulatory arrest (DHCA) in the rat. Our CPB circuit has several novel features, including a small priming volume, active cooling/rewarming processes, vacuum-assisted venous drainage, peripheral cannulation without thoracotomy or sternotomy, and an accurate means of monitoring peripheral tissue oxygenation. This small animal model provides a simple experimental system that could be used in future studies that use CPB and DHCA.

\section{MATERIALS AND METHODS \\ Animal Model}

The University of Iowa Institutional Animal Care and Use Committee approved this study. Fifteen Sprague-Dawley rats $(350-450 \mathrm{~g})$ from Charles River Laboratories (Wilmington, Mass) were housed under standard conditions. Nonfasted rats were anesthetized with chloral hydrate and isoflurane in $60 \%$ oxygen. During surgical preparation and recovery, anesthesia was maintained with isoflurane. Rats were allowed to spontaneously breathe air with an inspired oxygen fraction of $100 \%$. After the start of CPB, the oxygenator gas flow rate was held between 1 and $2.5 \mathrm{~L} / \mathrm{min}$ to maintain blood gases within the physiologic range. Animals were not intubated.

Surgical preparation consisted of cannulation of the left femoral artery for arterial inflow with a 20-gauge Angiocath catheter (Becton Dickinson, Franklin Lakes, NJ) and the right femoral artery for blood pressure monitoring with a 22-gauge Angiocath catheter via a cutdown. An injection of $400 \mathrm{IU} / \mathrm{kg}$ of porcine heparin was given after placement of the first catheter, and activated clotting time was maintained above 500 during CPB. The right common jugular vein was cannulated with a modified 4-hole 16-gauge Angiocath catheter that was advanced into the right atrium for venous drainage. A vacuum regulator with an applied pressure of $-30 \mathrm{~mm} \mathrm{H}_{2} \mathrm{O}$ was developed to facilitate increased venous drainage.

A rectal temperature of $18^{\circ} \mathrm{C}$ was achieved over 40 minutes, using CPBassisted cooling. At this temperature, rats still had a heart rate in the 30 s. If the heart rate was not 0 , we further cooled to cardiac arrest by echocardiogram (typically $14^{\circ} \mathrm{C}$ ). After reaching arrest, the circuit was turned off and rats were left in a DHCA state for 15 minutes. Next, rats were rewarmed to

\footnotetext{
From the Department of Cardiothoracic Surgery, University of Iowa Hospitals and Clinics, Iowa City, Iowa.

Disclosures: Authors have nothing to disclose with regard to commercial support.

Received for publication Oct 31, 2010; revisions received Dec 5, 2010; accepted for publication Jan 7, 2011; available ahead of print March 14, 2011.

Address for reprints: Robert Saeid Farivar, MD, PhD, University of Iowa Hospitals and Clinics, Department of Cardiothoracic Surgery, 200 Hawkins Dr, Iowa City, IA 52242 (E-mail: robert-farivar@uiowa.edu).

J Thorac Cardiovasc Surg 2011;141:1549-51

$0022-5223 / \$ 36.00$

Copyright (c) 2011 by The American Association for Thoracic Surgery doi:10.1016/j.jtcvs.2011.01.062
}

$34^{\circ} \mathrm{C}$ to $35^{\circ} \mathrm{C}$ over a period of 36 to 42 minutes using CPB-assisted rewarming, a heating blanket, and a heating lamp. The temperature gradient between the CPB circuit and body core did not exceed $10^{\circ} \mathrm{C}$. Simultaneously, $0.1 \mathrm{mEq}$ of sodium bicarbonate and $0.14 \mathrm{mEq}$ of calcium chloride were administered. After full rewarming, the remaining priming volume was reinfused and animals were weaned from CPB.

\section{Physiologic Parameter Measurement and Analysis}

The core and circuit temperature were continuously monitored with a dual temperature monitor (Figure 1, A) (DeBusk Temperature Systems; DeRoyal Technologies, Inc, New Tazewell, Tenn). An iStat Analyzer (Abbott Point of Care; Abbott Laboratories, Abbott Park, Ill) was used to analyze arterial blood gases ( $\alpha$-stat method), hemoglobin, and hematocrit. Samples were taken at baseline, $27^{\circ} \mathrm{C}$, and $18^{\circ} \mathrm{C}$ during the cooling stage (approximately 20 and 40 minutes, respectively) and at $27^{\circ} \mathrm{C}$ and $34^{\circ} \mathrm{C}$ during the rewarming stage (approximately 60 and 80 minutes, respectively). The DHCA duration was excluded from aforementioned time. During $\mathrm{CPB}$, the blood flow and venous saturation were continuously monitored. Targeted CPB flow was 100 to $120 \mathrm{~mL} \cdot \mathrm{kg}^{-1} \cdot \mathrm{min}^{-1}$, corresponding to about $70 \%$ of normal cardiac output.

\section{Experimental Circuitry}

The CPB circuit (shown in entirety in Figure 1) was primed with $12 \mathrm{~mL}$ of Plasma-Lyte solution (Baxter Healthcare, Deerfield, Ill) and consisted of the following components:

- Venous reservoir (Figure 1,F), connected to vacuum regulator (Ohmeda; Ohio Medical Corporation, Gurnee, Ill)

- Peristaltic pump (Figure 1, C) (Masterflex; Cole-Parmer, Vernon Hills, I11)

- Heat exchanger (Figure 1,E) (Sarns cardioplegic set; Terumo Cardiovascular Systems, Ann Arbor, Mich)

- Specifically designed rodent membrane oxygenator (Figure 1,D) (Arteriocyte, Cleveland, Ohio). The membrane oxygenator is constructed from 2 Plexiglas shells (Rohm and Haas Company, Philadelphia, Pa), which carry the diffusion membrane. The diffusion membrane is composed of 3 layers of polypropylene hollow-fiber mats (Jostra AG, Hirrlingen, Germany) fused in a crosswise fashion to improve oxygenation. The membrane has a gas exchange area of $558 \mathrm{~cm}^{2}$ and a priming volume of $4 \mathrm{~mL}$.

- Ultrasound flowmeter (Figure 1,B) (2N806 flow probe and T208 volume flowmeter; Transonic Systems, Ithaca, NY)

- Mixed venous oximeter (Oximetrix 3, Abbott Critical Care Systems)

- Silicone tubing with a 1.6-mm internal diameter (Cole-Parmer Instruments)

\section{RESULTS}

Fifteen rats were used for analysis. The average values of physiologically relevant parameters, taken immediately before the initiation of the cooling process (baseline) and at various stages of the procedure (ie, during cooling at 20 and 40 minutes and during rewarming at 60 and 80 minutes) are shown in Table 1.

Rats were typically cooled to $14^{\circ} \mathrm{C}$ to $18^{\circ} \mathrm{C}$ until complete arrest. The duration of DHCA was excluded from 


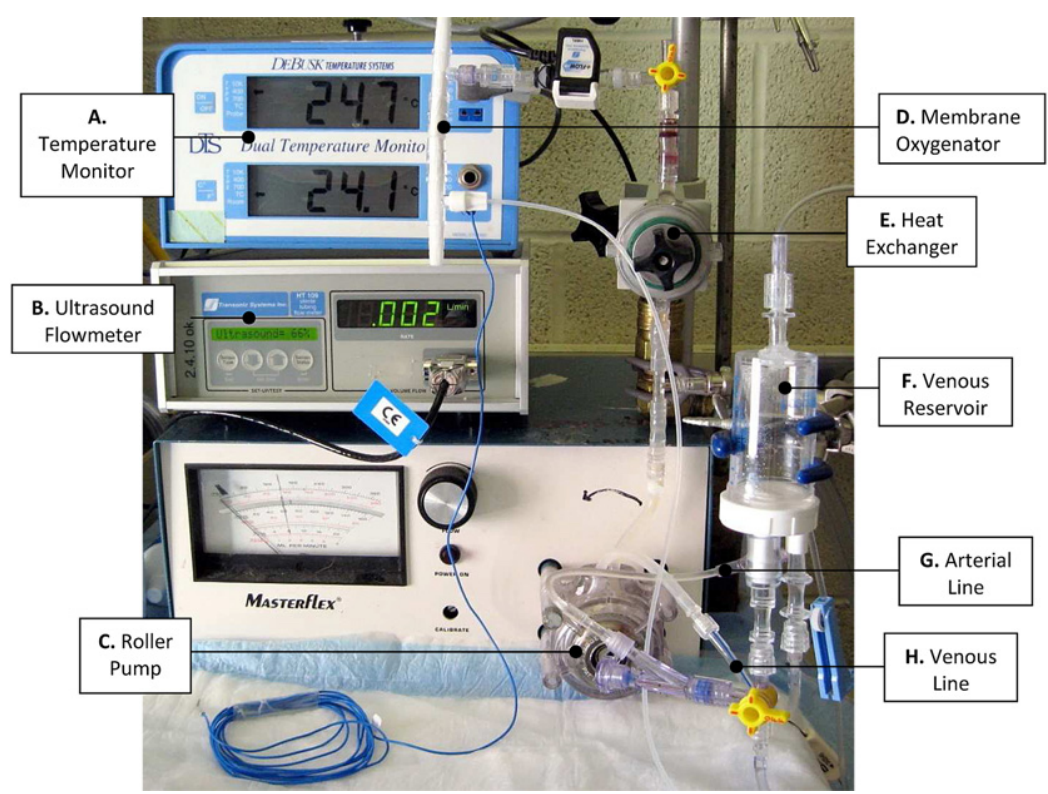

FIGURE 1. Cardiopulmonary bypass circuit: $A$, temperature monitor; $B$, ultrasonic flowmeter; $C$, roller pump; $D$, membrane oxygenator; $E$, heat exchanger; $F$, venous reservoir; $G$, arterial line; and $H$, venous line.

data analysis (15 minutes). Owing to hemodilution, some rats demonstrated a low mean arterial pressure and hemoglobin concentration as compared with baseline values. The mean arterial pressure dropped 20 points (on average) at the beginning of CPB but was subsequently maintained above $50 \mathrm{~mm} \mathrm{Hg}$ via epinephrine injection. Typically, during rewarming, mean arterial pressure remained above $50 \mathrm{~mm} \mathrm{Hg}$ without the use of inotropic agents. Lidocaine $2 \mathrm{mg}$ and calcium chloride $0.14 \mathrm{mEq}$ were routinely administered during rewarming. If animals had a $\mathrm{pH}$ less than 7.0, they received sodium bicarbonate $0.1 \mathrm{mEq}$.

\section{DISCUSSION}

We established a small animal model of CPB with DHCA in the rat. Our circuit has several innovative elements, including vacuum-assisted venous drainage, peripheral cannulation (without thoracotomy or sternotomy), active heating and cooling with a heat exchanger, a novel small membrane oxygenator, lack of need for intubation, a venous oximeter, and ultrasound flowmeter. With all these modifications, we were able to achieve 100 to $150-\mathrm{mL}$. $\mathrm{kg}^{-1} \cdot \min ^{-1}$ flow, which is relevant to clinically used CPB circuits.

TABLE 1. Physiologically relevant parameters of rats undergoing CPB with DHCA $(n=15)$

\begin{tabular}{|c|c|c|c|c|c|}
\hline \multirow[b]{2}{*}{ Time } & \multirow{2}{*}{$\begin{array}{c}\text { Baseline } \\
\text { 0 min }\end{array}$} & \multirow{2}{*}{$\begin{array}{l}\text { Cooling } \\
20 \mathrm{~min}\end{array}$} & \multicolumn{3}{|c|}{ Rewarming } \\
\hline & & & $40 \mathrm{~min}$ & $60 \mathrm{~min}$ & 80 min \\
\hline Hemoglobin $(\mathrm{g} / \mathrm{dL})$ & $13.3(1.4)$ & $7.3(1.3)$ & $6.6(0.9)$ & $6.3(1.1)$ & $6.3(0.8)$ \\
\hline Hematocrit & 39.7 (3.9) & $21.8(3.7)$ & $19.6(3.2)$ & $18.9(3.6)$ & $18.6(3.2)$ \\
\hline Flow (mL/min) & $49.1(7.5)$ & $40.6(12.5)$ & 39.7 (14.7) & $51.7(14.8)$ & $46.6(11.7)$ \\
\hline Temperature $\left({ }^{\circ} \mathrm{C}\right)$ & $33.8(0.8)$ & $27.1(1.6)$ & $17.9(0.7)$ & $27.8(3.2)$ & $35.5(0.8)$ \\
\hline Heart rate & $185.4(43.3)$ & $56.5(18.7)$ & $23(4.8)$ & $149.8(42.9)$ & $190.9(41.3)$ \\
\hline MAP & $69.9(20.1)$ & $49.8(18.3)$ & $51(16.1)$ & $61.8(15.3)$ & $59.8(7.4)$ \\
\hline $\mathrm{pH}$ & $7.15(0.12)$ & $7.12(0.11)$ & $7.14(0.08)$ & $7.18(0.14)$ & $7.15(0.14)$ \\
\hline $\mathrm{PCO}_{2}$ & $52.3(20.0)$ & $46.9(9.9)$ & $43.0(7.1)$ & $44.25(17.2)$ & $43.3(15.4)$ \\
\hline $\mathrm{Po}_{2}$ & $184.8(128.0)$ & $111.2(73.2)$ & $187.5(103.7)$ & $98(32.9)$ & $88.41(31.3)$ \\
\hline $\mathrm{HCO}_{3}^{-}$ & $18.7(4.8)$ & $15.8(2.9)$ & $15.5(3.5)$ & $17.9(7.6)$ & $15.6(6.9)$ \\
\hline Base excess & $-11.4(3.8)$ & $-12.3(4.2)$ & $-13.4(5.3)$ & $-9.1(8.4)$ & $-11.7(8.8)$ \\
\hline $\mathrm{SaO}_{2}$ & $95.3(5.4)$ & $87.6(11.8)$ & $96.9(2.6)$ & $92.1(3.9)$ & $90.2(6.1)$ \\
\hline $\mathrm{MVO}_{2}$ & $64.8(18.5)$ & $61.9(15.7)$ & $72(12.3)$ & $56.1(13.9)$ & $50.6(13.1)$ \\
\hline
\end{tabular}


Miniaturization of the membrane oxygenator represents the major limiting factor in the creation of a successful CPB model in small animals. Previous models have required high priming volumes to achieve acceptable hematocrit concentrations during the experiment. Our study uses a miniature novel oxygenator, modified venous cannula design, and reduction in the length of connection tubing, which allowed minimization of the priming volume, thus improving postoperative outcomes.

This model was developed to study neurocognitive models after DHCA. Thus, peripheral cannulation instead of thoracotomy or sternotomy is desired. Endotracheal intubation with mechanical ventilation was not performed. The absence of mechanical ventilation helped prevent the hypotension and bradycardia commonly observed at cessation of ventilation during CPB. Vacuum-assisted venous drainage, along with careful positioning of the venous outflow catheter, allowed an optimal venous drainage and provided an adequate perfusion flow rate of 100 to $120 \mathrm{~mL} \cdot \mathrm{kg}^{-1} \cdot \mathrm{min}^{-1}$, which is comparable with human flows. Ready access to femoral arteries reduced surgical trauma and resulted in decreased blood loss, in addition to better perfusion flow as compared with cannulation of the tail artery.

Full cardiac arrest was achieved at $14^{\circ} \mathrm{C}$ in all animals. Whereas others have used $9 \mathrm{mg}$ of esmolol and $0.2 \mathrm{mEq}$ of potassium chloride to reach cardiac arrest, ${ }^{4}$ we managed to achieve cardiac arrest with cooling alone (at a temperature of $15.7^{\circ} \mathrm{C} \pm 0.4^{\circ} \mathrm{C}$ ).

Certain limitations to this study remain, such as the absence of monitoring of pericranial temperature. Future modifications include the use of a hemoconcentrator to improve hematocrit. We will use this model in future studies to assess the neuroprotective effects of small molecules during DHCA.

\section{References}

1. De Lange F, Yoshitani K, Podgoreanu MV, Grocott HP, Mackensen GB. A novel survival model of cardioplegic arrest and cardiopulmonary bypass in rats: a methodology paper. J Cardiothorac Surg. 2008;3:51.

2. Modine T, Azzaoui R, Fayad G, Lacroix D, Bordet R, Warembourg H, et al. A recovery model in minimally invasive cardiopulmonary bypass in the rat. Perfusion. 2006;21:87-92.

3. Kim WG, Choi SH, Kim JH. Temperature control using a heat exchanger of a cardioplegic system in cardiopulmonary bypass model for rats. Artif Organs. 2008; 32:993-8

4. Ordodi VL, Paunescu V, Ionac M, Sandesc D, Mic AA, Tatu CA, et al. Artificial device for extracorporeal blood oxygenation in rats. Artif Organs. 2008;32:66-70. 